\title{
Effect of Pharmaceutical Care Services Provided by Clinical Pharmacists on Type-2 Diabetes Patients
}

\author{
Komal Choudhary ${ }^{1, *}$, Monika Mali1, Kamini Bhavsar ${ }^{1}$, Sunita Pawar², Arundhati Diwan², Supriya Barsode ${ }^{2}$ \\ ${ }^{1}$ Department of Clinical Pharmacy, Poona College of Pharmacy, Bharati Vidyapeeth University, Pune, Maharashtra, INDIA. \\ ${ }^{2}$ Department of Medicine, Bharati Vidyapeeth University, Pune, Maharashtra, INDIA.
}

Received: 28 Dec 2018;

Accepted: 19 Jan 2019

*Correspondence to:

Dr. Komal Choudhary, PharmD, Department of Clinical Pharmacy, Poona College of Pharmacy, Bharati Vidyapeeth University, Pune, Maharashtra, INDIA. Email: ckomal8087@gmail.com

Copyright: $\odot$ the author(s),publisher and licensee Indian Academy of Pharmacists. This is an open-access article distributed under the terms of the Creative Commons Attribution Non-Commercial License, which permits unrestricted non-commercial use, distribution, and reproduction in any medium, provided the original work is properly cited.

\begin{abstract}
Objectives: The study aimed to provide diabetic pharmaceutical care and evaluate the effect in terms of glycaemic control and blood pressure. Methods: Randomized, interventional, controlled and comparative clinical study was conducted recruiting a total of 152 type 2 Diabetes mellitus outpatients. The control group received only common clinical care from medical staff, whereas the intervention group received additional pharmaceutical care from clinical pharmacists. Biochemical data such as blood pressure, fasting and post prandial blood sugar were collected pre and post intervention. Knowledge, Attitude and Practice (KAP) questionnaire was administered to both groups before and after intervention. Changes in outcome were measured using t-test and independent t-test. For statistical significance, $P<0.05$ was considered. Results: In the intervention group, significant decrease in the FBS from $182.98 \pm 33.37$ (mean \pm SD) to $121.59 \pm$ 17.43, PPBS from $227.15 \pm 66.95$ to $156.67 \pm 18.50$, systolic BP from $137.61 \pm 22.95$ to $118.76 \pm 7.89$ and diastolic BP from $89.32 \pm 10.09$ to $80.53 \pm 6.91$ was observed and increase in the Knowledge, Attitude and Practices (KAP) of patient was observed from pre-questionnaire $24.57 \pm 2.8$ to post-questionnaire scoring $33.95 \pm 3.82$, which was statistically significant $(p<0.001)$, but no significant improvement in the control group was observed. Conclusion: Present study outcomes indicate that Pharmaceutical care provided by clinical pharmacists improves the control of diabetes and patient's knowledge, awareness and attitude about the disease and medicines can do productive changes in the glycemic control.
\end{abstract}

Key words: Diabetes, Pharmaceutical Care, Type 2 Diabetes, KAP, Clinical pharmacists.

\section{INTRODUCTION}

Diabetes is one of the world's leading chronic diseases with serious socioeconomic impact that requires a continuous medical care to prevent the risk of complications and associated co-morbidities. ${ }^{[1,2]}$ The International Diabetes Federation (IDF) estimates that 246 million adults worldwide have diabetes mellitus. The global prevalence of diabetes has risen from 108 million in 1980 to 422 million in 2014 with the rapid rise in middle-income and low-income countries. ${ }^{[3]}$

It has been proposed that age, obesity, regional adiposity, family history, genetic factors, sedentary lifestyle, lack of physical activity along with urbanization, industrialization, globalization can contribute to increase the risk of diabetes with considerable impact on quality of life and limits patient's routine activities in terms of physical, social and psychological well-being. ${ }^{[4]}$ Increased glucose levels may result in the development of micro and macro vascular complications and are associated with disease progression, hospitalization, premature disability and mortality. Several observational studies have shown that intensive glycaemic control will lead to improved outcomes in cardiovascular, cerebrovascular and peripheral vascular diseases. ${ }^{[-7]}$

Though Type 1 diabetes is the most common form of diabetes found in children, the availability of patients is less in Indian Scenario. Type 2 diabetes (non-insulin-dependent or adult-onset) resulting from insulin resistance is widely seen in both urban and rural areas. ${ }^{[8]} \mathrm{A}$ two to three fold increased risk of cardiovascular disease is associated with type 2 diabetes mellitus. Also, the long-term complications of diabetes are associated with high morbidity, high cost and decreased quality of life. The factors observed in poor glycaemic control include poverty, non-compliance, lack of knowledge and poor follow ups. ${ }^{[9]}$ Poor adherence results in the worsening of glucose control and increases the hospital admissions of patients due to diabetes complications. ${ }^{[10]}$

The increase in the cost of healthcare, disease burden, irrational use of medicines, non-availability of health care providers in sufficient numbers, especially in rural areas are all challenges we have to overcome. ${ }^{[1]}$ These challenges can be overcome by a clinical pharmacists with his/her knowledge and expertise in production, distribution, storage and dispensing of quality medicines and also promoting the rational medicine use, health promotion, managing medicines and drug therapy, providing patient instructions and counselling to patients to improve compliance with therapy, assisting patients in making effective self medicine choices and decisions for their health. ${ }^{[12]}$

Several studies have reported the positive impact of clinical pharmacist counseling on glycemic control and quality of life outcomes in diabetic population. ${ }^{[13-16]}$ Studies such as the Diabetes Control and Complication Trail (DCCT ${ }^{[17]}$ and United Kingdom Prospective Diabetes Study (UKPDS) ${ }^{[18,19]}$ have conclusively demonstrated that a goal of normalization of blood glucose significantly reduces the risk of complications. Therefore pharmacists specialized in this arena can make a significant and positive impact on the patients and health care system and who can provide counseling on disease, drug, lifestyle modifications, including diet and exercise and self-management of disease by periodic monitoring. ${ }^{[20]}$ 


\section{Choudhary, et al.: Pharmaceutical Care Services Provided by Clinical Pharmacists among Diabetes Patients}

Pharmaceutical care is direct, responsible provision of medication-related care with the purpose of achieving definite outcomes that improve a patients' quality of life. ${ }^{[2]]}$ The morbidity associated with DM can be reduced by proper knowledge about the disease, appropriate attitude and practices. ${ }^{[2]}$ Thus, this study aimed to evaluate the effects of pharmaceutical care services provided by clinical pharmacist on type- 2 diabetes patients.

\section{MATERIALS AND METHODS}

This study was approved by the Institutional Ethics Committee at Bharati Hospital and Research Centre, Pune. (REFERENCE BVDUMC/IEC/87)

\section{Study design}

A Randomized, interventional, controlled, comparative study of 8-months duration with one follow-up, was conducted on patients with Type 2 Diabetes Mellitus (T2DM), recruited from the general outpatient department of Bharati Hospital and Research Centre, Pune (Maharashtra, India), with an inclusion of patients with T2DM of either sex above 20 years of age and with hypertension, after an informed consent was obtained. Patients who were diagnosed with type1 Diabetes, pregnant or lactating women, those with physical or mental disability and who were not willing to give an informed consent were excluded. After recruitment, these patients were randomly distributed to Intervention Group (IG) or Control Group (CG). Patients in the control group received only clinical care from medical staff, whereas those in IG received additional pharmaceutical care from a clinical pharmacist. The primary endpoints in this study included improvement in Blood Pressure (BP), Fasting Blood Sugar (FBS), Post Prandial Blood Sugar (PPBS), Glycosylated Haemoglobin (HbA1c) along with impact on Knowledge Attitude Practice (KAP) of patients post intervention.

\section{Sample size}

A total of 200 patients were preliminarily assessed and as per the inclusion criteria, 160 patients were recruited into CG and IG, amongst whom, 8 patients dropped out from the study and 152 patients completed the study (76 patients for CG and 76 for IG).

\section{Data Collection}

Patients' demographic data, clinical data, medications and biochemical data, such as Blood Pressure, Fasting Blood Sugar (FBS), Post Prandial Blood Sugar (PPBS) and Glycosylated Haemoglobin (HbA1c) levels were collected using patient profile form along with the Knowledge, Attitude and Practice (KAP) questionnaire, in accordance with the physician's order before and after intervention.

\section{Pharmaceutical care services}

The intervention program included diabetic education to the patients. All patients in the IG were educated twice in this study (at the beginning and at the next follow-up, respectively) depending on the patients' knowledge, attitude and practice of T2DM, risk of diabetic complications, precautions of oral hypoglycaemic agents and insulin, signs and symptoms of hypoglycaemia, self-management of disease eg. Self-monitoring of blood glucose and a healthy lifestyle. Interviews included a face-to-face interview on the first visit and telephone or face-to-face interview on subsequent follow-up at the end of this study. In the interview, pharmacist discussed with each patient about their disease, medication adherence, self-monitoring of glucose control, exercise; and explained the side effects of anti-diabetic drugs; and reminded them of their next visit of follow-up. Individual patient's record files were maintained.

\section{Statistical analysis}

GraphPad QuickCalcs: $t$ - test calculator was used for statistical analysis and data was expressed as Mean \pm Standard deviation. Differences between control and intervention groups were evaluated using independent $t$-test and differences between baseline and endpoint outcome measures were determined using the paired $t$-test. $P<0.05$ was considered statistically significant.

\section{RESULTS}

Out of 160 patients, there were 152 patients who completed the study (76 patients in the intervention group and 76 patients in the control group). The other 8 patients were excluded from the study due to lost to follow-up. Figure 1 illustrates the flow of patients through the study and describes various stages at which data were collected. The age, gender, duration of diabetes, family history of diabetes, occupation, level of education and civilization for both the groups are presented in Table 1. Statistical analyses indicated that the groups were well matched ( $P>0.05$ in all cases).

\section{Clinical outcome measurements}

Among 152 patients, there was a significant decrease in fasting blood glucose in both the groups from $184.36 \pm 38.83$ to $180.82 \pm 15.26$ and $182.98 \pm$ 33.37 to $121.59 \pm 17.43$ between the baseline and final interview respectively with a difference considered to be statistically significant $(p<0.001)$ in the intervention group. In the control group there was a significant increase in post prandial blood glucose from $219.61 \pm 52.47$ to $222.46 \pm 53.43$ $(p>0.05)$; while in the intervention group there was a significant decrease in PPBG from $227.15 \pm 66.95$ to $156.67 \pm 18.50$ between the baseline and final interview, this difference is considered to be statistically significant $(p<0.001)$; presented in Table 2 .

There was a significant decrease in Systolic blood pressure in both the groups from $140.71 \pm 22.94$ to $136.42 \pm 23.8$ and $137.61 \pm 22.95$ to $118.76 \pm 7.89$ between the baseline and final interview respectively and this difference is considered to be statistically significant $(p<0.001)$ in the intervention group. According to the Diastolic blood pressure readings there was a significant decrease in both the groups from $90.79 \pm 7.79$ to $88.82 \pm 8.79$ and $89.32 \pm$ 10.09 to $80.53 \pm 6.91$ between the baseline and final interview respectively, with a statistically significant difference $(p<0.001)$ in the intervention group; presented in Table 3.

There was a significant decrease in knowledge, attitude and practices from $23.84 \pm 2.52$ to $23.18 \pm 2.81$ in the control group $(p>0.05)$ while in intervention group there was significant increase in knowledge, attitude and practices from $24.57 \pm 2.8$ to $33.95 \pm 3.82$ between the baseline and final interview respectively and this difference is considered to be statistically significant $(p<0.001)$; presented in Table 4.

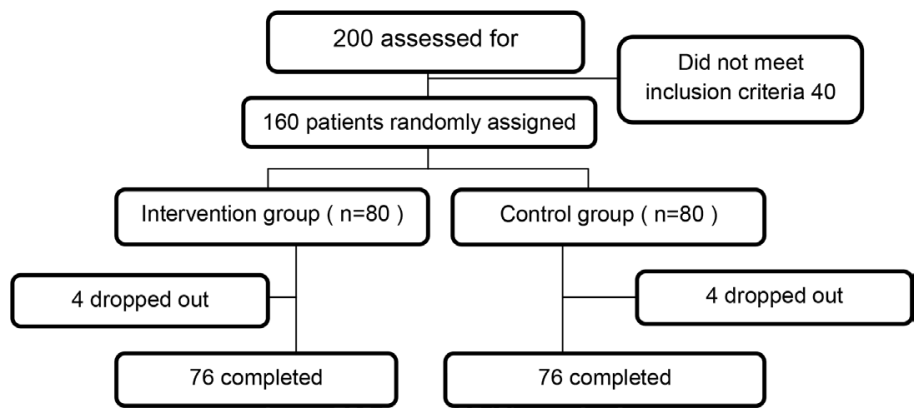

Figure 1: Flowchart of participants' screening for this study. 


\begin{tabular}{|c|c|c|c|}
\hline VARIABLES & $\begin{array}{l}\text { CONTROL } \\
n(\%)\end{array}$ & $\begin{array}{l}\text { INTERVENTION } \\
n(\%)\end{array}$ & $P$ VALUE \\
\hline \multicolumn{4}{|l|}{ Age groups } \\
\hline Below 30 & $2(3)$ & $0(0)$ & \multirow[t]{5}{*}{$0.739(p>0.05)$} \\
\hline $30-49$ & $16(21)$ & $15(20)$ & \\
\hline $50-69$ & $40(52)$ & $44(58)$ & \\
\hline Above 69 & $18(24)$ & $17(22)$ & \\
\hline Mean \pm SD & $57.23 \pm 15.71$ & $58.28 \pm 16.20$ & \\
\hline \multicolumn{4}{|l|}{ Gender } \\
\hline Male & $34(45)$ & $36(47)$ & \multirow[t]{2}{*}{$0.874(p>0.05)$} \\
\hline Female & $43(55)$ & $40(53)$ & \\
\hline \multicolumn{4}{|c|}{ Duration of Diabetes } \\
\hline Below 5 years & $20(26)$ & $21(28)$ & \multirow[t]{5}{*}{$0.999(p>0.05)$} \\
\hline $5-10$ years & $33(43)$ & $36(46)$ & \\
\hline $11-20$ years & $21(28)$ & $18(24)$ & \\
\hline Above 20 years & $2(3)$ & 1 (2) & \\
\hline Mean \pm SD & $9.06 \pm 12.78$ & $8.54 \pm 14.35$ & \\
\hline \multicolumn{4}{|c|}{ Family history of DM } \\
\hline Positive & $18(24)$ & $20(26)$ & \multirow[t]{2}{*}{$0.79(p>0.05)$} \\
\hline Negative & $58(76)$ & $56(74)$ & \\
\hline \multicolumn{4}{|l|}{ Occupation } \\
\hline Employed & $32(42)$ & $30(39)$ & \multirow[t]{2}{*}{$0.999(p>0.05)$} \\
\hline Unemployed & $44(58)$ & $46(61)$ & \\
\hline \multicolumn{4}{|c|}{ Level of Education } \\
\hline Illiterate & $38(50)$ & $26(34)$ & \multirow[t]{3}{*}{$0.999(p>0.05)$} \\
\hline School & $24(32)$ & $27(35)$ & \\
\hline College & $14(18)$ & $23(31)$ & \\
\hline \multicolumn{4}{|l|}{ Civilization } \\
\hline Rural & $52(68)$ & $46(61)$ & \multirow[t]{2}{*}{$0.999(p>0.05)$} \\
\hline Urban & $24(32)$ & $30(39)$ & \\
\hline
\end{tabular}

Note: Data presented as $\mathrm{n}(\%)$ or mean \pm standard deviation.

Abbreviations: DM: Diabetes mellitus; SD: Standard deviation.

\begin{tabular}{|c|c|c|c|c|}
\hline \multirow[b]{2}{*}{$\begin{array}{l}\frac{y}{0} \\
\frac{0}{0} \\
\frac{\sqrt{20}}{\frac{10}{10}} \\
>\end{array}$} & \multicolumn{2}{|c|}{ Control Group ( $n=76)$} & \multicolumn{2}{|c|}{ Intervention group $(n=76)$} \\
\hline & ஸे & $\frac{\frac{1}{d}}{\frac{4}{\alpha}}$ & 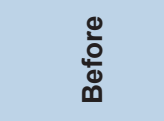 & $\frac{\grave{\Phi}}{\frac{\pi}{\alpha}}$ \\
\hline FBS & $184.36 \pm 38.83$ & $180.82 \pm 15.26$ & $182.98 \pm 33.37$ & $121.59 \pm 17.43$ \\
\hline$P$ value & \multicolumn{2}{|l|}{0.4512} & \multicolumn{2}{|l|}{$0.0001^{*}$} \\
\hline PPBS & $219.61 \pm 52.47$ & $222.46 \pm 53.43$ & $227.15 \pm 66.95$ & $156.67 \pm 18.50$ \\
\hline$P$ value & \multicolumn{2}{|l|}{0.7200} & \multicolumn{2}{|l|}{$0.0001^{*}$} \\
\hline
\end{tabular}

Note: Data presented as $n(\%)$ or mean \pm standard deviation, $\left({ }^{*}\right)$ indicates statistically significant.

Abbreviations: FBS: fasting blood sugar; PPBS: post prandial blood sugar
Table 3: Blood pressure-wise distribution of study population.

\begin{tabular}{|l|l|l|l|l|}
\hline Variables & \multicolumn{2}{|l|}{ Control Group $(\boldsymbol{n}=\mathbf{7 6})$} & \multicolumn{2}{l|}{ Intervention group $(\boldsymbol{n}=\mathbf{7 6})$} \\
\hline & Before & After & Before & After \\
\hline Systolic BP & $140.71 \pm 22.94$ & $136.42 \pm 23.8$ & $137.61 \pm 22.95$ & $118.76 \pm 7.89$ \\
\hline $\boldsymbol{P}$ value & 0.2009 & $0.0001^{*}$ & \\
\hline Diastolic BP & $90.79 \pm 7.79$ & $88.82 \pm 8.79$ & $89.32 \pm 10.09$ & $80.53 \pm 6.91$ \\
\hline $\boldsymbol{P}$ value & 0.1743 & $0.0001^{*}$ & \multicolumn{1}{|l}{} \\
\hline
\end{tabular}

Note: Data presented as $\mathrm{n}(\%)$ or mean \pm standard deviation, $\left({ }^{*}\right)$ indicates statistically significant.

Abbreviations: BP: blood pressure.

\begin{tabular}{|c|c|c|}
\hline \multicolumn{3}{|c|}{$\begin{array}{l}\text { Table 4: KAP Questionnaire Scoring-wise distribution of } \\
\text { study population. }\end{array}$} \\
\hline $\begin{array}{l}\text { KAP Questionnaire } \\
\text { Readings }\end{array}$ & $\begin{array}{l}\text { Control Group } \\
(n=76) \\
n(\%)\end{array}$ & $\begin{array}{l}\text { Intervention group } \\
(n=76) n(\%)\end{array}$ \\
\hline \multicolumn{3}{|l|}{ Pre-questionnaire Scoring } \\
\hline Mean \pm SD & $23.84(47.68) \pm 2.52$ & $24.57(49.14) \pm 2.8$ \\
\hline \multicolumn{3}{|l|}{ Post-questionnaire Scoring } \\
\hline Mean \pm SD & $23.18(46.36) \pm 2.81$ & $33.95(67.9) \pm 3.82$ \\
\hline$P$ value & 0.1706 & $0.0001^{*}$ \\
\hline
\end{tabular}

Note: Data presented as $\mathrm{n}(\%)$ or mean \pm standard deviation, $\left(^{*}\right)$ indicates statistically significant

Abbreviations: KAP: Knowledge, Attitude and Practice.

\section{DISCUSSION}

The interventions aimed at improving glycemic control. It was designed to measure the impact of a pharmaceutical programme on a wide range of clinical outcomes related to different aspects of healthcare in patients with type 2 diabetes mellitus. The levels of KAP and clinical outcomes of patients in terms of FBS, PPBS, Systolic and Diastolic blood pressure significantly improved in this study post intervention.

The statistical analysis indicated that, for both groups CG and IG, on the basis of age, gender, duration, family history, occupation, civilization and education level of diabetes, were well matched but statistically not significant $(p>0.05)$. It was observed that the number of female patients outnumbered male patients, with the mean duration of 5 to 10 years. Patients above 30 years were more prone to insulin resistance, posing as a risk factor for Type 2 Diabetes Mellitus. Patients with positive family history was compared to those with no family history. This may be explained by the fact that a previous family history is likely to increase awareness of the disease among other members of the family and those patients remain more informed regarding the management of the disease. Diabetic patients with higher education have positive self-esteem, better knowledge and understanding of the disease, its treatment and complications. Older age above 59 years, retirement, housewives, sedentary lifestyle all contribute as risk factors for diabetes. Education also plays an important role in controlling the disease. As most of the patients were from rural areas with lack of education and lower family income, they were unaware about the disease and its complication associated with it and ways to tackle the disease and management, which is similar to the study conducted somewhere else. ${ }^{[22-24]}$

In this study, there was a significant decrease in fasting blood sugar (FBS) in both the groups between the baseline and final interview. In the 


\section{Choudhary, et al.: Pharmaceutical Care Services Provided by Clinical Pharmacists among Diabetes Patients}

intervention group, this difference is considered to be statistically significant $(p<0.001)$, which is in line with the study conducted by Hua Shao et al. ${ }^{[24]}$ and Chidambaram Dhandapani et al. ${ }^{[25]}$ and that showed a significant improvement in FBS, in intervention group, compared to those in the control group. These results provide clinical evidence that pharmaceutical care has a positive role in T2DM management and suggest that routine participation of clinical pharmacist in medical teams for outpatients is of high therapeutic value. ${ }^{[24]}$

The findings showed that there was a significant increase in Post Prandial Blood Sugar levels (PPBS) in the control group while in the intervention group there was a significant decrease in PPBS between the baseline and final interview. The statistical analysis showed that the intervention group was statistically significant $(p<0.001)$ which is in agreement with the study conducted by Chidambaram Dhandapani et al. ${ }^{[25]}$ which showed that better glycemic control was obtained in the intervention group and that the pharmacist education sessions and follow up calls proved beneficial in reducing mean PPBS levels significantly.

This study showed that there was a significant decrease in systolic and diastolic blood pressure in both the groups between the baseline and final interview and thus revealed a positive conclusion of pharmaceutical care to control hypertension in patients with diabetes. Moreover, in the intervention group, this difference is considered to be statistically significant $(p<0.001)$ for both systolic and diastolic blood pressure, which is consistent with the studies conducted by Hua Shao et al. ${ }^{[24]}$ and Winifred Aitalegbe Ojieabu et al. ${ }^{[26]}$ these studies demonstrated that the mean values of systolic and diastolic blood pressure were significantly decreased in both groups, but in the control group there was an increase of about 1 unit from the baseline in the mean value of systolic blood pressure.

KAP scoring showed that, there was a significant decrease in knowledge, attitude and practices between the baseline and final interview in the control group, whereas, in the test group there was a significant rise in knowledge, attitude and practices between the baseline and final interview. The statistical analysis presented the intervention group to be statistically significant $(p<0.001)$ and were in accordance with studies conducted by Chidambaram Dhandapani et al. ${ }^{[25]}$ and Noohu Abdulla Khan et al. ${ }^{[27]}$ indicating that the improvement in diabetic patients' knowledge, awareness and attitude about the disease can do productive changes in glycemic control.

\section{Limitation and Future directions}

The pharmaceutical care provided to patients through counseling and teaching, in this study has not only proved in a positive manner, the need of a clinical pharmacist in a clinical setting, but also their necessity to improve lifestyle and knowledge of diabetic patients.

A few limitations faced included certain clinical variables for assessment and comparison like, HbA1c and Lipid levels, which are critical parameters of outcome. Lack of multiple follow ups due to time limitation prevented the provision of long term pharmaceutical care. As the population was mostly from rural areas, the data mainly presented rural population, which limited its extrapolation on overall mixed population from urban sector as well. This will indeed, in future, help the medical groups and care systems to consider integrating these new and effective pharmacist-led services with other valuable components of diabetes care in a way that it increases patient satisfaction with care as well as improves the quality, cost and safety of the increasingly personalized and complex diabetes care regimens that will emerge in the next decade.

\section{CONCLUSION}

Pharmaceutical care provided by the pharmacist to T2DM patients improved the overall clinical outcomes in diabetic patients. Education and counseling by clinical pharmacist results in better care of patients with chronic, long term diseased conditions and helps them improve their quality of life. This study provided evidence on the value of clinical pharmacist as a critical member of the medical team who can effectively provide Pharmaceutical care and help in achieving positive clinical outcomes.

\section{ACKNOWLEDGEMENT}

Authors would like to thank Vincey Kurian (Pharm D), Anju Thomas (Pharm D) and Sophia Mathew (Pharm D) for their critical review and support.

\section{CONFLICT OF INTEREST}

The authors declare no conflict of interest.

\section{ABBREVIATIONS}

Nil.

\section{REFERENCES}

1. Gulliford MC, Charlton J. Is relative mortality of type 2 diabetes mellitus decreasing?. Am J Epidemiol. 2009;169(4):455-61.

2. The global challenge of diabetes. Lancet. 2008;371(9626):1723.

3. Mathers $C D$, Loncar $D$. Projections of global mortality and burden of disease from 2002 to 2030. PLoS Med. 2006;3(11):e442.

4. Chandalia M, Abate N, Garg A, Stray-Gunderson J, Grundy SM. Relationship between generalized and upper body obesity to insulin resistance in Asian Indian men. J Clin Endocrinol Metab. 1999;84(7):2329-35.

5. Yajnik CS. The lifecycle effects of nutrition and body size on adult adiposity, diabetes and cardiovascular disease. Obes Rev. 2002;3(3):217-24.

6. Yajnik CS, Fall CH, Coyaji KJ, Hirve SS, Rao S, Barker DJ, et al. Neonatal anthropometry: the thin-fat Indian baby. The Pune Maternal Nutrition Study. Int J Obes Relat Metab Disord. 2003;27(2):173-80.

7. Krishnaveni GV, Hill JC, Veena SR, Leary SD, Saperia J, Chachyamma KJ, et al. Truncal adiposity is present at birth and in early childhood in South Indian children. Indian Pediatr. 2005;42(6):527-38.

8. http://www.who.int/news-room/fact-sheets/detail/diabetes

9. Marc A, Ronald P, Guy E, Bruce H, Redekop K. Health related quality of life and treatment satisfaction in Dutch patients with type 2 diabetes. J Diabetes Care. 2002;25(3):458-63.

10. Cramer JA, Pugh MJ. The influence of insulin use on glycemic control: How well do adults follow prescriptions for insulin?. Diabetes Care. 2005;28(1):78-83.

11. Erratum $P$. The role of the pharmaceutical industry in promoting patient education. Patient Educ Couns. 1995;26(1):245-9.

12. Worley M, Schommer J, Brown L, Hadsall R, Ranelli P. Pharmacists' and patients' roles in the pharmacist-patient relationship: Are pharmacists and patients reading from the same relationship script?. Res Soc Admin Pharm. 2007;3(1):47-69.

13. Coat SEA. Management of patients with type 2 diabetes by pharmacist in primary care clinics. Ann Pharmacother. 1998;32(6):636-41.

14. Tiggellar JM. Protocol for the treatment of essential hypertension and type 2 diabetes mellitus by pharmacist in ambulatory care clinics. Drug Intel Clin Pharm. 1987;21(6):521-9.

15. Zettervall DK. Recognition, treatment and management of acute diabetes complications in long term care facilities. The Consultant Pharmacist. 2000;15(4):397-416.

16. Jaber LA, Halappy H, Fernet M, Thammalapalli S, Divakaren H. Evaluation of pharmaceutical care model on diabetes management. Ann Pharmacother. 1996;30(3):238-43.

17. Diabetes Control and Complication Trial Group. Influence of intensive diabetes treatment on quality of life outcomes in the diabetes control and complication trial. Diabetes Care. 1996;19(3):195-203.

18. U.K. Prospective Diabetes Study Group. Quality of life in type 2 diabetic patients is affected by complications but not by intensive policies to improve blood glucose or blood pressure control. Diabetes Care. 1999;22(7):1125-36. 
19. U.K. Prospective Diabetes Study Group. Glycemic control with Diet, Sulfonylurea, Metformin or Insulin in patients with type-2 Diabetes Mellitus. J Am Med Assn. 1999;281(21):2005-12.

20. India census statistics. (Internet). Available from: http://www.censusindia.gov.in/ Dist File/datasheet0606.pdf

21. Binhemd TA. Diabetes mellitus: knowledge, attitude, practice and their relation to diabetes control in female diabetics. Ann Saudi Med. 1992;12(3):247-51.

22. Sriram S, Chack LE, Ramasamy R, Ghasemi A, Ravi TK, Sabzghabaee AM. Impact of pharmaceutical care on quality of life in patients with type 2 diabetes mellitus. 2011;16(Suppl 1):412-8.

23. AIMazroui NR, Kamal MM, Ghabash NM, Yacout TA, Kole PL, McElnay JC. Influence of Pharmaceutical care on health outcomes in patients with type 2 diabetes mellitus. Br J Clin Pharmacol. 2009;67(5):547-57.
24. Shao H, Chen G, Zhu C, Chen Y, Liu Y, He Y, et al. Department of Pharmacy, Zhongda Hospital; Effect of Pharmaceutical care on clinical outcomes of outpatients with type 2 diabetes mellitus. Patient Prefer Adherence. 2017;11:897903.

25. Chidambaram D, Sumy S, Arul KSG. Role of Clinical Pharmacist in the Management of Type II Diabetes Mellitus and its Outcomes. IJPTP. 2014;5(3):977-983.

26. Winifred AO, Bello SL, Arute JE. Evaluation of Pharmacists,Education and counseling impact on patients, clinical outcomes in a diabetic setting. J Diabelog. 2017;8(1):7-11.

27. Akbar N, Talieha A, Dhingra S, Noman-Ul-Haq. Assessment of Knowledge and Dietary Misconceptions among Diabetic Patients. J Pharm Pract Community Med. 2016;2(1):9-15.

Cite this article as: Choudhary K, Mali M, Bhavsar K, Pawar S, Diwan A, Barsode S. Effect of Pharmaceutical Care Services Provided by Clinical Pharmacists on Type-2 Diabetes Patients. J Pharm Pract Community Med. 2019;5(1):22-6. 